\title{
ANÁLISE DE TEMPOS NA AUTOMAÇÃO E CONTROLE NO \\ LABORÁTORIO - CIM ATRAVÉS DO ENSINO PRESENCIAL E \\ REMOTO - ONLINE
}

\author{
Francisco de Assis Toti-francisco.toti01@fatec.sp.gov.br \\ Marcos Vinicius Fernandes Pontes-marcos.pontes@fatec.sp.gov.br \\ José Josimar de Oliveira - jose.oliveira90@fatec.sp.gov.br \\ Amilton Joaquim Cordeiro de Freitas - Amilton.freitas@fatec.sp.gov.br \\ Faculdade de Tecnologia de Sorocaba "José Crespo Gonzales" \\ Endereço: Av. Eng. Carlos Reinaldo Mendes, 2015 \\ CEP:18013280 - Cidade: Sorocaba - Estado - SP
}

Resumo: A alta demanda de manufatura de produtos individualizados incentivou a implementação da manufatura de produtos mistos. Assim, em uma planta industrial pode-se produzir diferentes tipos de produtos na mesma célula de manufatura, denominado sistema flexível de manufatura. Para isso, no processo de ensino aprendizagem tanto a fundamentação teórica como a prática são essenciais, em especial nas disciplinas do eixo de produção em que as ementas contemplam o tópico estudo de tempos e métodos por cronometragem, o qual é imprescindivel para o balanceamento de linha, definido como o ponto chave para se atingir no menor tempo o máximo de produção. $O$ presente trabalho tem por objetivo apresentar a metodologia de ensino por prática presencial e remota, no formato online, sobre o controle e automação do processo utilizando o laboratório de sistema de manufatura integrada por computador - CIM. Resultados obtidos indicaram que os alunos obtiveram uma visão ampla do sistema produtivo na parte técnica, bem como, a aplicação direta do conteúdo de várias disciplinas para resolver o estudo de caso proposto. Quanto a experiência de acompanhar a prática de forma remota através de softwares de simulação, um dos problemas apontado foi o atraso durante o desenvolvimento dos estudos de caso. Entretanto, pode-se considerar como boa a aceitação dos alunos para a prática dessa modalidade de laboratório, indicando que estudos devem ser aprofundados sobre o desenvolvimento de um modelo híbrido (presencial e remoto-online) para prática de laboratório.

Palavras-chave: CIM. Simulação. Tempos e Método. Ensino Remoto. 


\title{
1 INTRODUÇÃO
}

A produção diversificada em menor tempo, baixo custo e com o máximo de qualidade é a meta de todo setor produtivo para permanecer num mercado globalizado e cada vez mais competitivo. As empresas de manufatura enfrentam uma intensa concorrência global e para permanecerem competitivas "São instadas a aplicar uma abordagem rápida e adaptável para produção de produtos personalizados com grandes variedades e lotes pequenos, que contribuem para aumentar a complexidade do processo" (GIVEHCHI et al., 2017). Aliado a isso, "Para aumentar a produção geralmente há modernização de processos ou aquisição de novos equipamentos, tendo como objetivo a redução de custos, focado nas perdas do processo" (GUERRA \& FABRO, 2019).

Atualmente a produção está abarcada em tecnologias avançadas tais como: projetos e processos auxiliados por computador, automação e sistemas de informação, sendo determinantes para o aumento da produção com padrão de qualidade e menor custo para o setor de consumo.

\begin{abstract}
A demanda do mercado exige soluções envolvendo a troca do modo clássico de controle centralizado da produção para um controle distribuído totalmente descentralizado, cada entidade (por exemplo, produto, recurso) mantém seus próprios objetivos interligados com os objetivos globais do lote no nível do chão de fábrica, como por exemplos: produção, tempo de produção ou balanceamento da carga (BORANGIU et al., 2014).
\end{abstract}

Nesse contexto, a educação atual nos seus diversos níveis de formação, em especial na área da engenharia busca com uma visão objetiva o formando do amanhã, em que "O setor da educação vem se adequando para que o ensino seja cada vez mais integrativo e dinâmico, onde o educador é o elo principal para distribuir e gerenciar o conhecimento através da tecnologia de informação" (TOTI et al., 2019). Nos cursos de graduação, disciplinas principalmente relacionadas a engenharia de produção que contemplam automação e controle do processo, tais como: estoque, tipos de produtos, layout, equipamentos, processos, montagem, manutenção, transporte e o controle de qualidade, a prática de laboratório com a tecnologia da informação torna-se imprescindível. A automação do processo ocorre entre máquinas, sensores e outros equipamentos que estão instalados para o desenvolvimento de projeto e fabricação de determinado produto, tendo como objetivo principal a redução da interferência humana no processo. Na literatura, vários autores abordam o sistema de manufatura integrada por computador - CIM, podendo ser flexível ou não que utilizam computadores para controlar o desenvolvimento desde a simulação até a finalização de determinado produto.

"Muitas previsões foram feitas em torno do desenvolvimento tecnológico, onde se acreditava na possibilidade da retirada completa da presença do homem do ambiente fabril. Apesar do alto nível de automatização nas indústrias, o poder decisório ainda pertence às pessoas, que devem ser capazes de adaptar-se às novas tecnologias" (COELHO \& CARVALHO, 2017).

Diante do exposto acima, fica evidente a necessidade da integração de novas tecnologias em práticas de laboratórios, entretanto, como conciliar atividade prática presencial e remota para o aluno ir se adequando a esse desenvolvimento tecnológico, parece não ser tarefa fácil e aliado a situação atual, os estudos devem ser aprofundados. 


\section{ESTUDO DE TEMPOS, MOVIMENTOS E MÉTODOS}

O conhecimento do tempo que envolve as etapas de fabricação e/ou a montagem de determinado produto é fundamental para a gestão da produção. $\mathrm{O}$ controle do tempo de operação de equipamentos e máquinas num sistema produtivo flexível é de suma importância, dentre outros para o balanceamento de linha. São vários os métodos existentes para a medição e determinação dos tempos, tais como: dados históricos, amostragem, cronometragem, comparação, estimativa e MTM (Methods Time Measurement), "Sendo que os mais comuns e usados são os métodos de comparação, de MTM e de cronometragem" (VASCO GASPAR, 2016). O método de comparação é aplicado para uma única produção e de baixa precisão. O método MTM está estruturado no gerenciamento do tempo, sendo extremamente útil para classificar o conteúdo do trabalho e otimizar os sistemas de produção prospectivos (antes do início da produção) e durante uma produção em execução. "Na indústria não é aplicado de forma abrangente, pois o treinamento intensivo e o alto esforço para gerar estudos de tempo são tidos como obstáculos" (MORLOCK et al., 2017). O método de cronometragem é a técnica de obter os tempos de processos que, numa análise mais completa se tornará uma cronoanálise.

"Como qualquer outra técnica ou ciência, a cronometragem possui uma terminologia especial, portanto, alguns dos termos especiais empregados na cronometragem ou estudo de tempos devem ser definidos para propiciar a melhor compreensão dos resultados" (FELIPPE et al., 2012).

Sendo assim, a engenharia de manufatura define o método de trabalho a ser aplicado no controle e automação do processo objetivando o máximo de eficiência. Etapas de processos podem apresentar tempo morto (ocioso) ou sobrecarregados que influenciam no melhor aproveitamento dos recursos disponíveis do sistema produtivo, ou seja, influenciando na capacidade do setor produtivo. "Engenharia de fábrica: também denominada engenharia industrial ou engenharia de manufatura é o setor que deve estabelecer o método de trabalho ou o processo mais eficiente" (PEINADO \& GRAEML, 2007).

\section{OBJETIVO}

Diante do exposto acima, fica evidente que o conteúdo a ser ministrado com auxílio de prática presencial em laboratório proporcionará uma visão abrangente de todo o processo para o aluno. Entretanto, também a tecnologia, por exemplo, no campo da engenharia caminha para ser cada vez mais para a área da simulação e remota. Aliado a isso, diante da pandemia em que o mundo enfrenta atualmente, impôs de certa forma o isolamento das pessoas nos diversos setores da sociedade e no setor acadêmico, a aplicação de ensino a distância EAD foi uma solução encontrada, visto que é crescente a modalidade. $\mathrm{O}$ objetivo do presente trabalho foi avaliar os resultados iniciais obtidos do aprendizado dos alunos de disciplina com prática presencial de laboratório, a qual passou a ser ministrada de modo remota-online, utilizando softwares de simulação. 


\section{METODOLOGIA}

A metodologia utilizada nesse trabalho, foi aplicada nas disciplinas de tecnologia de fabricação mecânica e manufatura avançada, dos cursos superiores da Faculdade de Tecnologia de Sorocaba - Fatec-So, utilizando no laboratório FESTO a plataforma multidisciplinar iCIM (intelligence Computer Integrated Manufacturing), que tem como características a tecnologia de controle, design e leiaute, planejamento de produção, controle de processos e simulação. A célula de manufatura em escala de laboratório é formada por cinco estações de trabalho: sistema de transporte com paradas (esteira), armazém automático com robô, a estação de montagem automática com robô Mitsubishi, controle de qualidade e a estação flexível de manufatura contendo centro de usinagem EMCO Concept Mill com comando Sinumerik 840D e robô Mitsubishi. Os softwares de simulação utilizados foram o CIROS® Studio 6.4 e o FUSION $360 ®$ Autodesk, ambos de versão educacional. Foram desenvolvidos estudos de casos FP01 e FP02.

\subsection{Estudo de casos}

No primeiro estudo de caso foi desenvolvido o fluxograma do processo denominado FP01 utilizando a programação e tempo padrão, considerando o armazém, esteira, robô e usinagem CNC para peça de código P01 utilizando a programação de usinagem FESTO. A figura 1 ilustra a esquematização do leiaute da célula de manufatura iCIM.

Figura 1 - Esquematização da célula de manufatura iCIM - FESTO, Software CIROS.

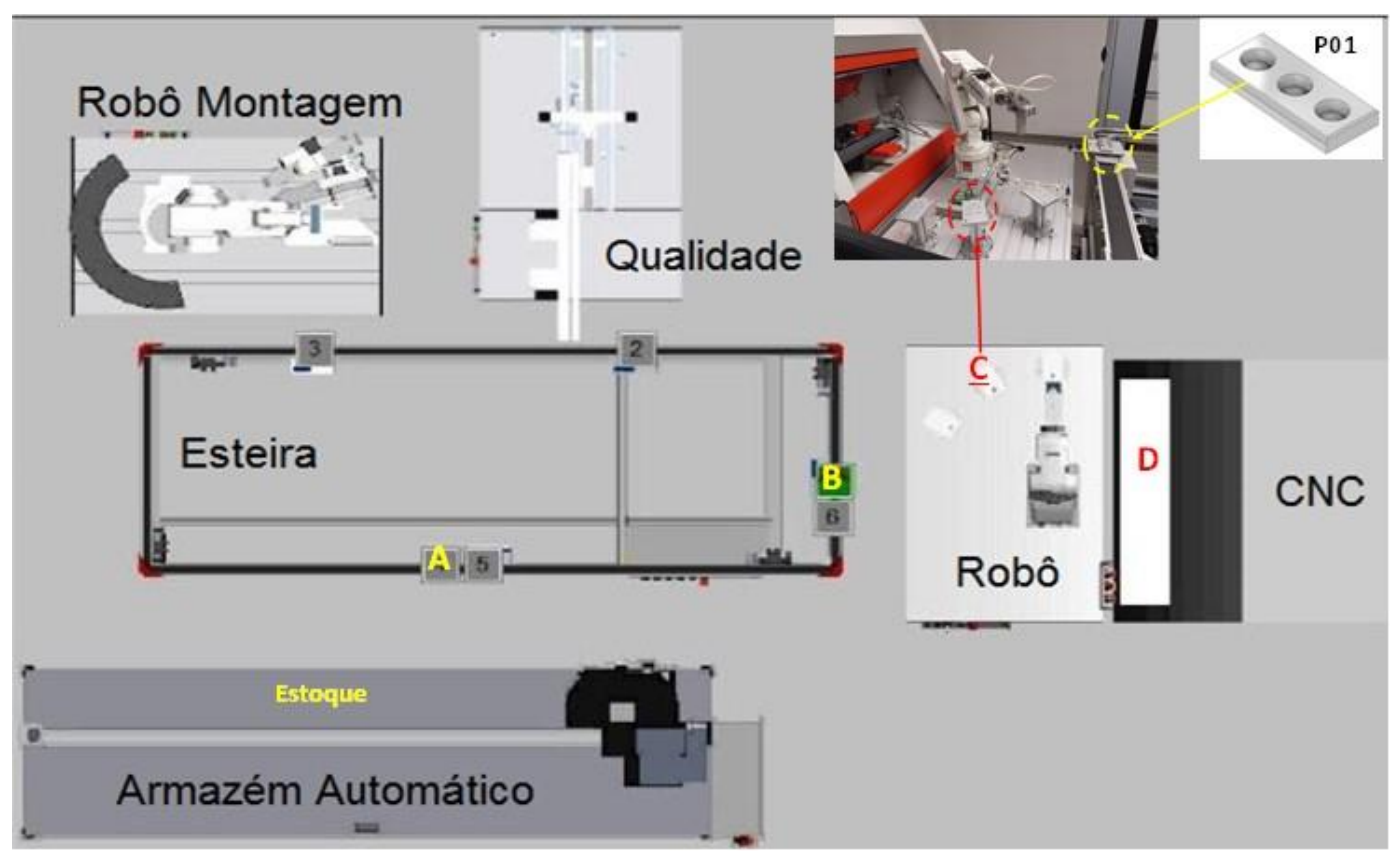

Fonte: Autoria própria.

Após a cronometragem dos tempos das etapas conforme a sequência das referências: estoque, A, B, C, D, C, B, A, estoque, em função das velocidades, deslocamentos e tempo de usinagem padronizados, foi criada a tabela e o fluxograma do processo conforme mostra a tabela 1 e a figura 2 , respectivamente. 


\section{Evento On-line}

Tabela 1 - Descrição das etapas do processo FP01.

\begin{tabular}{|c|c|c|}
\hline Etapa & Descrição & $\begin{array}{l}\text { Duração } \\
\text { (min) }\end{array}$ \\
\hline 1 & $\begin{array}{l}\text { Baseplate com matéria-prima de código FS1 retirada do estoque pelo } \\
\text { braço robótico e posicionada na esteira na referência A }\end{array}$ & 0,18 \\
\hline 2 & Movimentação da esteira até o baseplate ficar posicionado na referência B & 0,33 \\
\hline 3 & $\begin{array}{l}\text { Braço robótico movimenta baseplate da referência } \mathrm{B} \text { até a referência } \mathrm{C} \\
\text { (base para posicionamento entre a esteira e o centro de usinagem) }\end{array}$ & 0,18 \\
\hline 4 & $\begin{array}{l}\text { Braço robótico movimenta baseplate da referência } \mathrm{C} \text { até a referência } \mathrm{D} \\
\text { (mordente do centro de usinagem) }\end{array}$ & 0,35 \\
\hline 5 & Operação de usinagem da peça P01 na matéria-prima & 5,1 \\
\hline 6 & Braço robótico movimenta baseplate da referência $\mathrm{D}$ até a referência $\mathrm{C}$ & 0,23 \\
\hline 7 & Braço robótico movimenta baseplate da referência $\mathrm{C}$ até a referência $\mathrm{B}$ & 0,18 \\
\hline 8 & Movimentação da esteira até o baseplate ficar posicionado na referência A & 1,12 \\
\hline 9 & $\begin{array}{l}\text { Braço robótico armazena no estoque (posição inicial) o baseplate com o } \\
\text { produto FS1 retirado da referência A }\end{array}$ & 0,23 \\
\hline & Tempo centesimal total do processo & 7,92 \\
\hline
\end{tabular}

Fonte: Autoria própria.

Figura 2 - Fluxograma do processo FP01
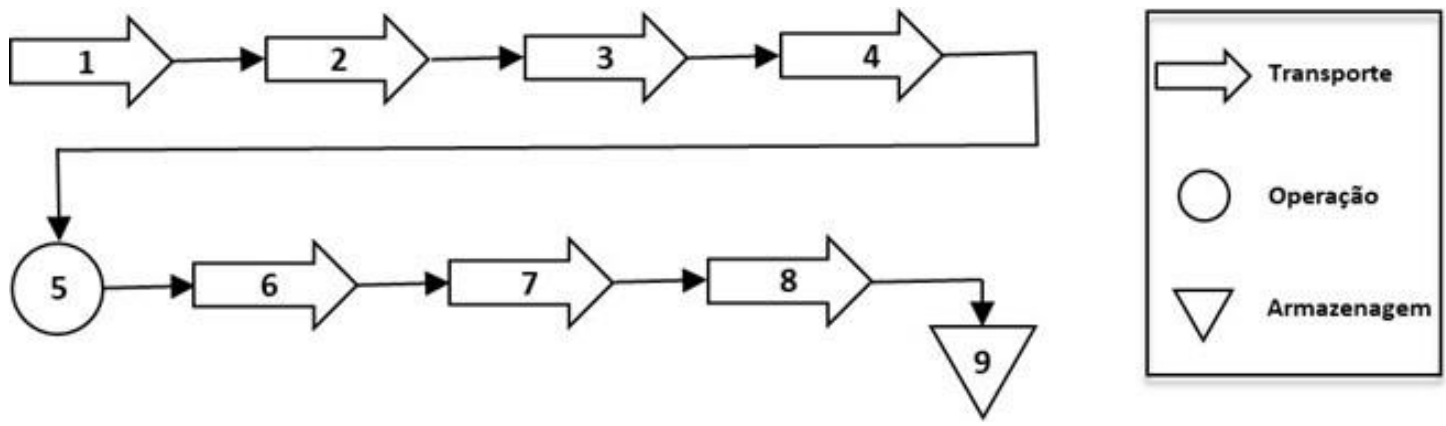

Fonte: Autoria própria.

Na sequência, ocorre a alteração da velocidade de movimentação do robô que envolvem as etapas 3, 4, 6, 7, mantendo a velocidade da esteira e o tempo de usinagem, avaliando a performance no tempo total do processo. Como o foco desse estudo de caso é transporte e operação de usinagem, a estação de qualidade e montagem entra em outra etapa do estudo.

$\mathrm{O}$ segundo estudo de caso denominado $\mathrm{FP} 02$, primeiramente é realizada a modelagem 3D, a programação e a simulação de usinagem utilizando o software FUSION 360, do elemento de máquina denominado bucha de código P02, conforme ilustra a figura 3. 
Figura 3- Elemento de máquina Bucha. (a) desenho de fabricação e modelagem 3D e (b) simulação CAM.

(a)
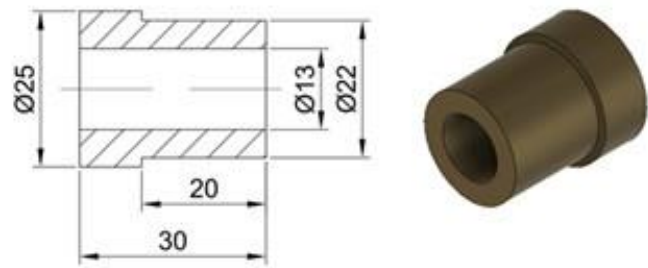

(b)

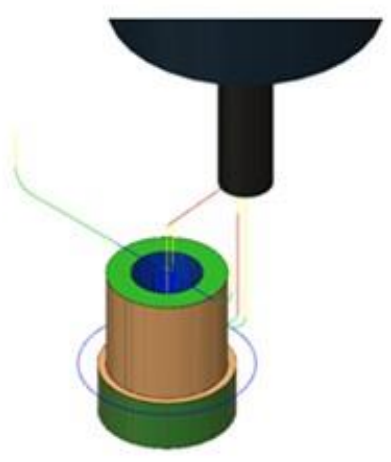

Fonte: Autoria própria.

Posteriormente, a matéria prima da peça P02 é inserida no armazém da célula conforme localizado na figura 1, em local pré estabelecido e o programa gerado de usinagem é transferido para a máquina $\mathrm{CNC}$, onde são realizados testes (try-out) antes da programação ser utilizada na produção. Com isso, tem-se o tempo de usinagem da peça $\mathrm{P} 02$ que em seguida é inserido no fluxograma do processo FP01. Nessa etapa, é confrontado o tempo de usinagem obtido pela simulação com o tempo real de usinagem para avaliar a diferença e quanto incide no tempo total de produção. "O tempo de usinagem mostrado pelo software, pode apresentar diferença considerável em relação ao tempo de usinagem real, causada pelas características de cada máquina ferramenta" (YAMAMOTO et al., 2017). A tabela 2 mostra os tempos de simulação de usinagem das peças P01 e P02.

Tabela 2 - Tempos de simulação de usinagem.

\begin{tabular}{c|c|c|}
\hline Peça & Usinagem & Tempo (min) \\
\hline P01 & simulação & 5,1 \\
\hline P02 & simulação & 2,7 \\
\hline
\end{tabular}

Fonte: Autoria própria. 


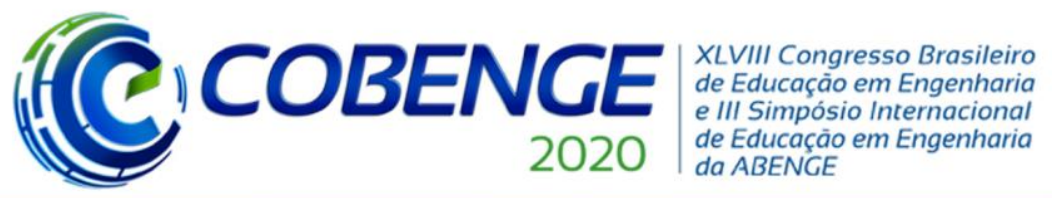

"Os desafios para formar hoje o engenheiro do amanhã"
$\mathrm{O1}$ a $\mathrm{O} 3$ de dezembro Evento On-line

Na última etapa, é avaliado o balanceamento de linha para produção das duas peças objetivando o máximo de produtividade, inserindo a estação de qualidade e construindo um novo fluxograma do processo. Por fim, essa metodologia é aplicada com acompanhamento do docente e auxiliar de docente de laboratório.

\subsection{Ensino remoto - online}

A metodologia apresentada no tópico anterior foi planejada para ser desenvolvida de forma presencial, entretanto, devido a situação mundial atual, mais precisamente no estado de São Paulo com o isolamento social, as aulas passaram a ser ministrada de modo remoto-online, nos horários estabelecidos no início do $1^{\circ}$ semestre de 2020. A metodologia foi adequada e aplicada utilizando o software Teams ${ }^{\circledR M i c r o s o f t}$ em conjunto com os softwares mencionados anteriormente. As figuras 4 e 5 ilustram as imagens da área de trabalho do software Teams e de componentes físicos alocados no laboratório iCIM e seus componentes virtuais utilizados para o ensino remoto - online, respectivamente.

Figura 4 - Área de trabalho do software Teams na aula prática de tempos e método.

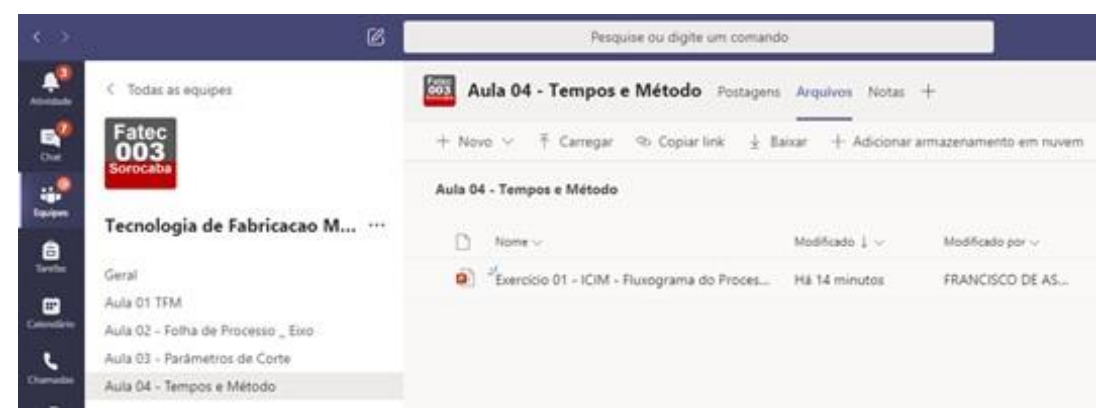

Fonte: Autoria própria.

Figura 5 - Imagem de componentes físicos e virtuais do laboratório iCIM.

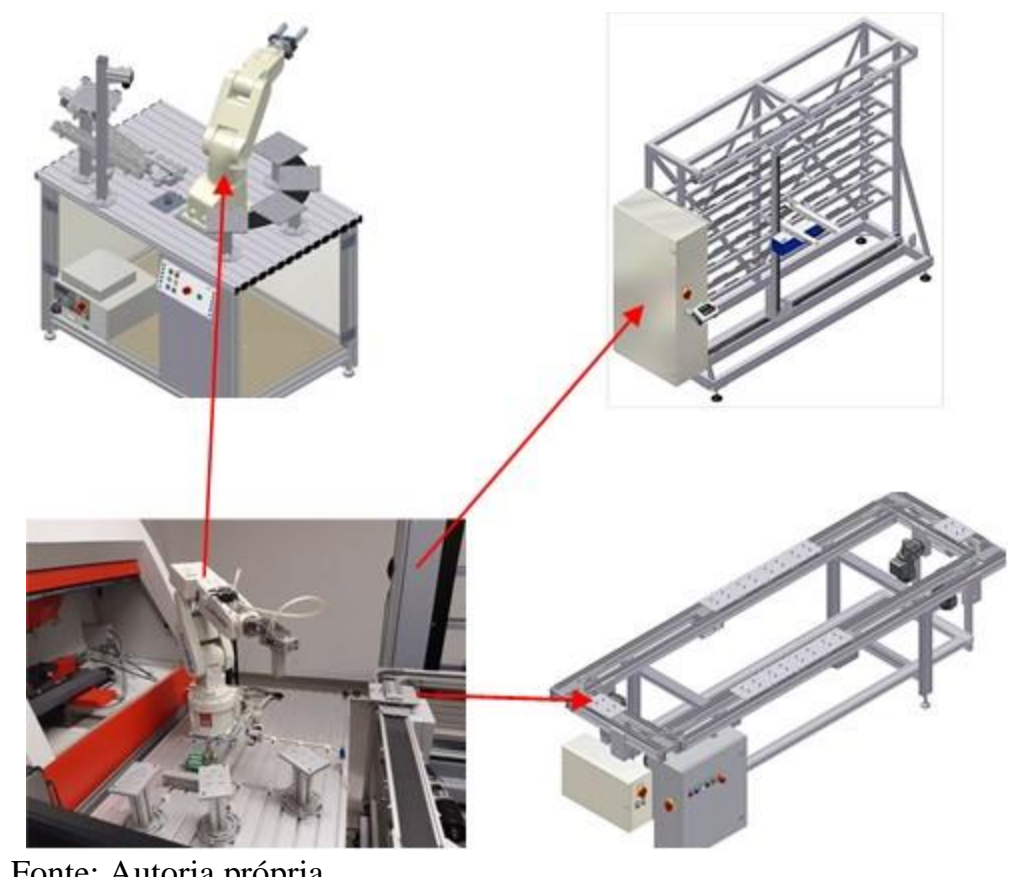

Fonte: Autoria própria. 


\section{CONSIDERAÇÕES FINAIS}

Os resultados parciais obtidos das práticas de laboratório ministradas de forma remotaonline indicaram bom desempenho acadêmico, bem como, boa aceitação dos alunos no ambiente virtual, visto que, os recursos utilizados reproduziam o ambiente físico do laboratório. Entretanto, dúvidas como, por exemplo, sobre a fixação das peças no baseplate e no mordente para usinagem in loco seriam mais fáceis de serem esclarecidas.

O compartilhamento de arquivos entre professor e aluno através do software Teams apresentou vantagens, dentre as quais podemos citar, do professor verificar se o aluno está desenvolvendo a atividade na aula, bem como, auxiliá-lo na resolução de suas dúvidas. Também vale destacar, o problema enfrentado do delay entre a explicação do conteúdo pelo professor e o acompanhamento do aluno em que o ritmo de apresentação teve que ser adequado em comparação ao sistema presencial.

Diante do exposto, os resultados obtidos nessa prática de ensino-aprendizagem proposta para o laboratório em questão, indicam que estudos devem ser aprofundados para a migração gradativa para um sistema híbrido (prática presencial e remota-online). Com isso, também adaptaremos os alunos às novas tecnologias de trabalho, as quais certamente serão implantadas mais rapidamente em função da situação em maior ou menor grau de isolamento que o mundo está vivenciando.

\section{Agradecimentos}

Os autores agradecem ao Centro Paula Souza por prover o regime de jornada integral - RJI e a BR Festo MBX Suporte Didatic pela liberação de licenças de softwares.

\section{REFERÊNCIAS}

BORANGIU, Theodor et al. Distributed manufacturing control with extended CNP interaction of intelligent products. J Intell Manuf. p. 1065-1075, DOI 10.1007/s10845-0130740-3, 2014.

COELHO, Fabio Junior Santos; CARVALHO, Rogerio Atem. Estudo sobre o desenvolvimento e tendências futuras da Manufatura Integrada por Computador (CIM) através de análise bibliográfica e bibliométrica. GEPROS. Gestão da Produção, Operações e Sistemas, Bauru, Ano 12, nº 3, jul-set, p. 107-130, 2017.

FEIPPE, Adélia Denísia et al. Análise descritiva do estudo de tempos e métodos: uma aplicação no setor de embaladeira de uma indústria têxtil. Simpósio de excelência em gestão e tecnologia. IX SEGET, 2012.

GUERRA, Bruno Almeida; FABRO, Elton. Indústria 4.0 como ferramenta na engenharia de manutenção com base na metodologia TPM. Scientia Cum Indústria, V. 7, N. 2, pp. 23. http://dx.doi.org/10.18226/23185279.v, 2019.

GIVEHCHI, Mohammad; AZEDH, Haghighhi; WANG, Lihui. Cloud-DPP for distributed process planning of mill-turn machining operations. Robotics and Computer-Integrated Manufacturing journal homepage: www.elsevier.com/locate/rcim, 2017. 
MORLOCK, Friedrich et al. Teaching Methods-Time Measurement (MTM) for Workplace Design in Learning Factories. Procedia Manufacturing 9 , p. 369 - 375, 2017.

PEINADO, Jurandir \& GRAEML, Alexandre. Administração da produção: operações industriais e de serviços Curitiba, UnicenP, 2007.

TOTI, Francisco de Assis et al. Banco de dados aplicado nas disciplinas da área da manufatura avançada em cursos de graduação. Congresso Brasileiro de Educação em Engenharia, COBENGE, Fortaleza, 2019.

VASCO, Gaspar. Análise de Tempos e Métodos numa Linha de Produção de Autocarros. Dissertação (mestrado), Universidade de Coimbra, Portugal. 2016.

YAMAMOTO, Yuki; AOYAMA, Hideki; SANO, Noriaki. Development of accurate estimation method of machining time in consideration of characteristics of machine tool. Journal of Advanced Mechanical Design, Systems, and Manufacturing, v. 11, n. 4, p. JAMDSM0049-JAMDSM0049, 2017.

\title{
ANAL YSIS OF TIME IN AUTOMATION AND CONTROL IN THE LABORATORY - CIM THROUGH PRESENTIAL AND REMOTE EDUCATION - ONLINE
}

\begin{abstract}
The high demand for the manufacture of individual products encouraged the implementation of the manufacture of mixed products. Thus, in an industrial plant, different types of products can be produced in the same manufacturing cell, called the flexible manufacturing system. For this, in the teaching-learning process, both theoretical and practical foundations are essential, especially in the disciplines of the production axis in which the menus contemplate the topic study of times and methods by timing, which is essential for line balancing. , defined as the key point to achieve maximum production in the shortest time. This work aims to present teaching methodology by face-to-face and remote practice, in the online format, about the control and automation of the process using the computer integrated manufacturing system laboratory - CIM. Results obtained indicated that the students obtained a broad view of the productive system in the technical part, as well as the direct application of the content of several disciplines to solve the proposed case study. As for the experience of monitoring the practice remotely through simulation software, one of the problems pointed out was the delay during the development of the case studies. However, the acceptance of students for the practice of this type of laboratory can be considered as good, indicating that studies should be deepened on the development of a hybrid model (in-person and remote-online) for laboratory practice.
\end{abstract}

Keywords: CIM. Simulation. Times and Method. Remote Teaching. 